proof was needed, but impossible to supply. It is curious that, as in Gödel's theorem, it is in these declarations of impotence that mathematicians sometimes reach their zenith. In demonstrating, and accepting, the impossible, mankind (paradoxically) breasts its summit.

Throughout history, the axiomatic method has gained favour, and advanced from strength to strength. Seen in full vigour in Euclid's geometry, it appears again for mechanics in the hands of Archimedes. Centuries later, something akin ran in the mind of Descartes, and in our own century (1908) we find it in the Axiomatik of Carathéodory's thermodynamics. What more fitting for it to support the great structure of arithmetic, and the aesthetic satisfaction of David Hilbert's systematic foundations? Yet that is just what it has failed to do, and what Gödel showed it fundamentally incepable of doing. It is nothing less than that which constituted the core of his original paper, with the forbidding title "On Formally Undecidable Propositions of Principia Mathematica and Related Systems". All this germinated in the mind of the young member of the Vienna Circle. When events shattered that distinguished group, Princeton came to the rescue, and Harvard acclaimed Kurt Gödel at his truo stature.

The authors of the present book begin by discussing the problem and absolute proofs of consistency, giving an example wherein such a proof is successful. This entails, en route, the systematic codification of formal logic. A reader with some little competence in the sentential and existential calculus will have no particular difficulty in following the train of thought thus far. Then comes the idea of mapping, and its use in mathematics. It is exactly here that the power of Gödel is so remarkable. We are familiar with the processes of projective geometry, or those involving the theorem of Pappus, wherein an abstract structure of relations in a domain (A) can bo mirrored as holding in another domain (B). (In this particular case the transform is between points and lines.) What Gödel did was to map statements 'about' arithmetic as expressions 'in' arithmetic. In other words, he managed to project the meta-mathematics of arithmetic upon arithmetic itself. This method amounts in effect to making meaningful statements about a formalized mathematical system; it says something about mathematies, but plainly not belonging to it. Meta-language and meta-science sometimes present difficulties to the British way of thinking. Perhaps a very crude analogy would be the distinction between history and historiography, which is well accepted among scholars.

The end-result of Gödel's achievement is that arithmetic is incomplete. The way in which this remarkable conclusion is reached is by proving that there is at least one mathematical truth which cannot be said to follow from the axioms, and yet can be established meta-mathematically from outside.

We are thus faced with severe limitations in the whole axiomatic method itself, and everything built upon it. One cannot specify once for all a fixed set of axioms to shore up and bear the whole load.

There is, as the authors point out in a significant footnote (pp. 99-100), a throw-back to a type of Platonic realism. Gödel would seem to accept the existence of classes and concepts as real objects whether in fact we have 'realized' them or not. This may have wide repercussions, for it may prove to be in line with Heisenberg's primordial matter (after the manner of Anaximander), which he considers may be needed to extricate the quantum theory from its present philosophical confusion. Supposedly, such an entity would exist independently of our thoughts about it.

For what is little more than an essay on a vast subject, the writers have done astonishingly well. The proof-reading must have been as near faultless as human frailty can accomplish, since a minor misprint in such a strange land would lead many a careful inquirer to despair. To make Gödel's theorem more accessible is something supremely worth while, and this book is the way to do it.

$$
\text { F. I. G. RAwLINS }
$$

\section{ORGANIZATION AND METHODS}

\section{Organization and Methods}

A Service to Management. Edited by G. E. Milward. Pp. xxxii $+408+4$ plates. (London: Macmillan and Co., Ltd.; New York: St. Martin's Press, Tne., 1959.) 63s. net.

$T$ HIS is essentially a practical book and gives the essence of the experience in organization and methods work of nine large commercial companies. Mr. Milward has done an excellent job in producing such a readable volume and one which does not show evidence of its rather mixed parentage. As one completely untrained in office management, yet who has had to accept responsibility for the many "administrative' aspeets of a large scientific institution, I can testify to the value of organization and methods procedures as described in this book in simplifying and often in reducing the ever-increasing paper work.

The book is concerned essentially with the practice of "Organization and Methods", the types of people required to carry out its procedures, their training and methods of working. It does not ignore the human factors which form such an important part in the operation of any organization. Its range is from the setting-up of an organization and methods department to information about types of office machines and their efficient use, and even to some matters of detail such as the optimum size for an office desk. In these days, when there is such a plethora of office machines and office systems on offer, it is extremely valuable to have, in convenient form, the product of the experience of leading companies.

A feature of the book which is claimed to be unique is a chart on the field of office machinery. This sets out diagrammatically the seven basic clerical operations and the machines which carry out or assist them, while the pros and cons of mechanization are discussed in the text. There is much in this book of interest and value not only to the managers of large commercial offices but also to those who have to incorporate in their organizations or institutions some efficient system of collection of data, recordkeeping, ordering, etc. The index does not do justice to the book-especially one on this subject. For example, 'Pros and cons of mechanization' is indexed under ' $P$ ', with no reference under ' $M$ ' ; 'Glossary of arithmetical terms' is under ' $G$ ', with no reference under ' $A$ ', and so on. $\quad \mathrm{E}$. $\mathrm{S}$. Hiscocrs 